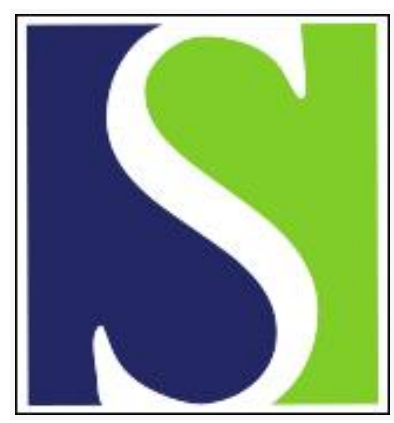

Scand J Work Environ Health 2008;34(4):235-238

https://doi.org/10.5271/sjweh.1273

Issue date: Aug 2008

Inequalities in health, social causation and the role of occupation

by Kristensen $P$

Affiliation: Scandinavian Journal of Work, Environment \& Health, Topeliuksenkatu 41 a A, FI-00250 Helsinki, Finland. petter.kristensen@stami.no

Refers to the following texts of the Journal: $2008 ; 34(2): 81-82$

2008;34(4):250-259 2008;34(4):260-266

The following articles refer to this text: $2009 ; 35(6): 429-436$;

2013;39(2):134-143; 2014;40(1):1-3

Key terms: editorial; health; inequality; occupation; social causation

This article in PubMed: www.ncbi.nlm.nih.gov/pubmed/18820820

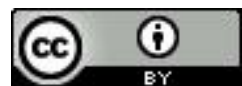




\section{Inequalities in health, social causation and the role of occupation}

Social inequalities in health have been recognized as an important public health issue for decades. Several developed countries have ambitions to improve national policies in order to reduce such inequalities (1, 2). Occupation and work conditions are important elements in these preventive strategies. This priority makes sense. Employment in itself promotes health, and health inequalities between those employed and those not employed are substantial. In addition, there are clear social gradients with respect to workplace physical, chemical, psychosocial, and organizational qualities. An example is the importance raised in a recent editorial in the Scandinavian Journal of Work, Environment \& Health (3) about solid employment as regards both health and health inequalities.

Still, estimates of how important the qualities of job exposure are with respect to social inequalities in health are mostly lacking. After the appearance of the Black Report (4), solid evidence has been presented showing that social causation is more important than health selection in explaining the gradient, with few exceptions. Therefore, conditions related to socioeconomic status determine health and not vice versa. The uncertainty concerns the impact of workplace qualities (exposures) in relation to other factors that may be unevenly distributed according to socioeconomic status, for example, nonoccupational material and psychosocial conditions, health-related personal behavior, and health care facilities. A simple model (figure 1) illustrates this phenomenon without specification of the nonoccupational mediators between socioeconomic status and health. There are exceptions to our lack of knowledge, and the most important are documented relationships between psychosocial conditions at work and cardiovascular morbidity and other health outcomes (5). I believe there is a simple explanation for why we know so little about the role of occupation and job exposures. Traditionally, occupational epidemiology has focused on the study of

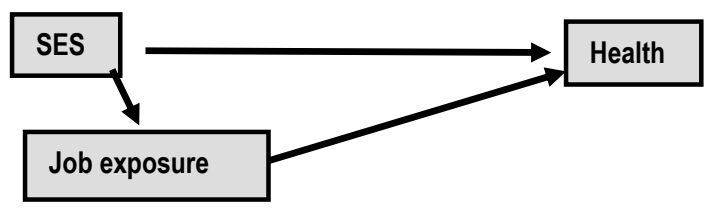

Simple model

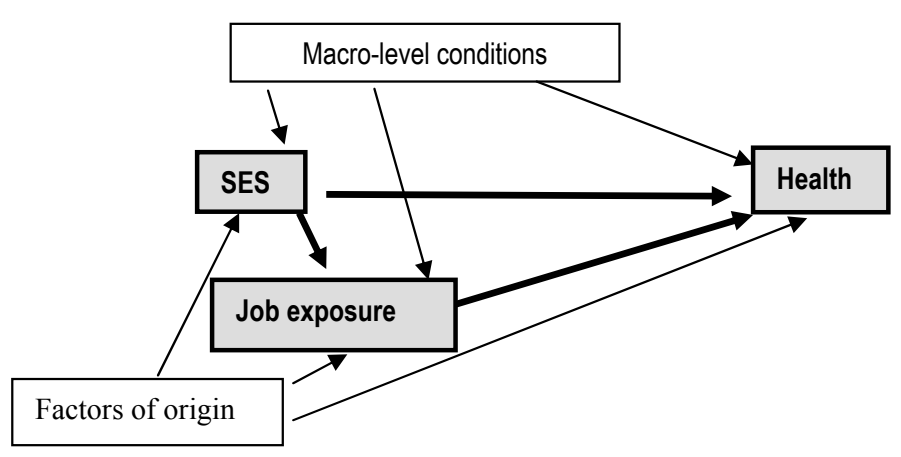

Extended model

Figure 1. The role of job exposure with respect to social inequalities in health in two models. (SES = socioeconomic status) 
causal relationships between adverse exposures and disease. In this research, socioeconomic status is a potential confounder that is generally dealt with through restriction. Obtaining a lack of contrast in socioeconomic status in study populations is an important aim. Alternatively, analytic adjustment is preferred, with "adjusted for socioeconomic status" ending up as a table footnote.

There is obviously a need for contrast in socioeconomic status if the role of occupation is to be studied with respect to social inequalities in health. Analytically this approach can be followed by using a series of regressions $(6,7)$ according to a simple causal model (figure 1). The social gradient in health is estimated in models with and without job exposures, and the difference (gradient reduction) tells us the fraction of social causation being explained by job. The model illustrates that "job exposures" are both an effect (of socioeconomic status) and a determinant (of health). A suggested analytic alternative is therefore to use such joint models as path models or structural equation modeling $(6,7)$. However, thus far, they have not yet been used much in the study of social inequalities in health.

In this issue of the Scandinavian Journal of Occupational Health, Mehlum and her coworkers seek to explain the role of job exposures for socioeconomic gradients in musculoskeletal pain (8). In a series of regression models, they provide several estimates showing, for example, that job autonomy can explain one-fourth $(25 \%)$ and one-third $(34 \%)$ of the differences in neck-shoulder pain among unskilled female and male workers, respectively. This study was cross-sectional, with all of the information on job exposure and musculoskeletal outcomes based on self report, and the authors took into consideration several caveats. The results and inferences are dependent on both possible measurement error and model specifications. Reverse causation (neck-shoulder pain determining socioeconomic status) is a possibility. More plausible is the suggestion that pain causes a change in exposure (job autonomy). This possibility can be viewed as a measurement error of exposure (the exposure indicator being a proxy that underestimates true adverse exposure, before pain occurred). The most likely effect would be that the role of occupation in explaining the socioeconomic gradient would be underestimated. On the other hand, common method bias could induce a falsely inflated estimate of the role of job exposure if associations between self-assessed job autonomy and self-reported neck-shoulder pain were biased.

There could also be other problems related to more fundamental issues of social inequalities in health. Research in this field after the Black Report has led to vast increases in understanding and empirical evidence (9). One major contribution is the concept of the influence of life course, or how biological and social factors operate at different stages of life and thereby contribute to adult health inequalities (10). The life course concept has led to renewed interest in indirect selection $(11,12)$. Indirect selection is a mechanism involving early factors that could influence social inequalities in health. These factors are not involved in direct causal relationships between socioeconomic status and health, but instead form third variables responsible for their covariation. The main hypothesis concerns personal attributes such as cognitive ability, personality, and bodily and mental fitness (11). We have reason to believe that indirect selection can be an important mechanism with which to explain social gradients in health, because some of these factors are strong determinants of educational and occupational achievement and, at the same time, determine later health. It follows that this explanation comes about at the expense of social causation and, disregarding indirect selection, could lead to an overestimation of the role of occupation in explaining social inequalities in health. This extended model is illustrated by adding "factors of origin" to the causal diagram presented in figure 1.

Does this possibility mean that the estimates of the impact of job autonomy on social inequalities in neck-shoulder pain are exaggerated because coping ability or coping strategies were not considered in the analyses by Mehlum et al (8)? As yet, we have no clear answer. The empirical evidence to support or refute the potential explanatory power of indirect selection is scarce. Furthermore, there could be continuous feedback between social factors and health in a life course perspective, making distinctions between selection and social causation even more complex (12). It is obvious that cross-sectional studies 
are not suitable for answering these questions. The nearest we might get could be studies based on birth cohorts. The 1958 British birth cohort (the National Child Development Study) provides good examples of possibilities and complexities in applying extended causal models. Power et al (13) found that childhood cognitive ability explains a substantial part of social inequality in psychological distress at the age of 33 years. This is not the full story. In a more recent follow-up, psychological distress was found to be associated with poor work conditions (decision latitude) at the age of 45 years and, in turn, influenced depression and anxiety (14). These analyses were not intended to quantify the role of psychosocial job characteristics in explaining health gradients, but the example illustrates the complexity of feedback between social factors and health over time. One could add to model complexity by including the potential for interaction between the work environment and the third factors responsible for indirect selection. In fact, psychosocial factors (eg, effort-reward imbalance or decision latitude), considered as elements of the work environment, are clearly integrations of environmental and personal factors.

Another major development in inequality research (9) has been the increased focus on multilevel issues and on studying the effects of the macro-social environment (contextual factors) on health (figure 1). Finnish studies of the severe economic decline during the early 1990s have provided important knowledge of the effects of organizational downsizing on subsequent mortality and other health outcomes (15). Virtanen and his coworkers have provided another example of possible contextual workplace effects in this issue of the Scandinavian Journal of Work, Environment \& Health (16). They found large differences in sickness absence between employees in four factories within a single company, differences that were only partly explained by common determinants such as gender, age, work ability, and physical and psychosocial work conditions. The explanation could be that there were contextual differences in the cultural handling of absence across the factories. Many suggest that contextual effects can be analyzed using multilevel methods, but this approach has also been criticized $(17,18)$.

Will the model used by Mehlum et al (8) be sufficient as a basis for policies to prevent health inequalities? The simple problem could be that the role of social causation (including job qualities) in explaining health gradients would be overestimated. A more complex and possibly more important problem could be that preventive strategies would be misled if interplay between social and biological origin, the macroenvironment, and qualities of the work environment were not considered. The Scandinavian Journal of Work, Environment \& Health will be happy to consider publishing studies that can contribute to this important topic.

\section{References}

1. Mackenbach JP. Socio-economic inequalities in health in Western Europe: from description to explanation to intervention. In: Siegrist J, Marmot M, editors. Social inequalities in health: new evidence and policy implications. Oxford (United Kingdom): Oxford University Press; 2006. p 223-50.

2. Costa G. Health inequalities among occupations: epidemiologic hints for labour and social protection policies. (English summary). Med Lav. 2005;96(suppl):s7-s27.

3. Burdorf A. The importance of solid employment for health [editorial]. Scand J Work Environ Health. 2008;34(2):81-2.

4. Townsend P, Davidson N. Inequalities in health: the Black Report and the health divide. Harmondsworth (United Kingdom): Penguin Books; 1982.

5. Siegrist J, Theorell T. Socio-economic position and health: the role of work and employment. In: Siegrist J, Marmot M, editors. Social inequalities in health: new evidence and policy implications. Oxford (United Kindgom): Oxford University Press; 2006. p 73-100.

6. Baron RM, Kenny DA. The moderator-mediator variable distinction in social psychological research: conceptual, strategic, and statistical considerations. J Pers Soc Psychol. 1986;51(6):1173-82.

7. De Stavola BL, Nitsch D, dos Santos Silva I, McCormack V, Hardy R, Mann V, et al. Statistical issues in life course epidemiology. Am J Epidemiol. 2006;163(1):84-96.

8. Mehlum IS, Kristensen P, Kjuus H, Wergeland E. Are occupational factors important determinants for socio-economic inequalities in musculoskeletal pain? Scand J Work Environ Health. 2008;34:350-9.

9. Siegrist J, Marmot M, editors. Social inequalities in health: new evidence and policy implications. Oxford (United Kingdom): Oxford University Press; 2006. 
10. Power C, Kuh D. Life course development of unequal health. In: Siegrist J, Marmot M, editors. Social inequalities in health: new evidence and policy implications. Oxford (United Kingdom): Oxford University Press; 2006. p 27-53.

11. Mackenbach JP. Genetics and health inequalities: hypotheses and controversies. J Epidemiol Community Health. 2005;59:268-73.

12. Goldman N. Social inequalities in health: disentangling the underlying mechanisms. Ann NY Acad Sci. 2001;954:11839.

13. Power C, Stansfeld SA, Matthews S, Manor O, Hope S. Childhood and adulthood risk factors for socio-economic differentials in psychological distress: evidence from the 1958 British birth cohort. Soc Sci Med. 2002;55:1989-2004.

14. Stansfeld SA, Clark C, Caldwell T, Rodgers B, Power C. Psychosocial work characteristics and anxiety and depressive disorders in midlife: the effects of prior psychological distress. Occup Environ Med. In press [doi:10.1136/oem.2007.036640].

15. Vahtera J, Kivimäki M, Pentti J, Linna A, Virtanen M, Virtanen P, et al. Organisational downsizing, sickness absence, and mortality: 10-town prospective cohort study. BMJ. 2004;328:555-9.

16. Virtanen P, Siukola A, Luukkaala T, Savinainen M, Arola H, Nygård C-H, et al. Sick leaves in four factories: do characteristics of the employees and the working conditions explain the differences in sickness absence between workplaces? Scand J Work Environ Health. 2008;34:360-6.

17. Kaufman JS. Socioeconomic context [commentary]. Epidemiology. 2006;17:4-5.

18. Oakes JM. The (mis)specification of neighborhood effects: causal inference for a practicable social epidemiology. Soc Sci Med. 2004;58:1929-52.

\author{
Scandinavian Journal of Work, Environment \& Health \\ Petter Kristensen, Associate Editor \\ [E-mail; petter.kristensen@stami.no]
}

